\title{
The Relationship between Imagery and Perception of Success among Male and Female High School Athletes 中學生運動員採用表象訓練對成功感覺的關係
}

\author{
Sze Ying HENG \\ Ministry of Education Malaysia, MALAYSIA \\ Mohd. Sofian Omar Fauzee \\ University Putra Malaysia, MALAYSIA \\ Kim Geok SOH \\ University Putra Malaysia, MALAYSIA
}

邢思莹

馬來西亞教育局

莫哈末蘇菲安

馬來西亞博特拉大學

蘇金玉

馬來西亞博特拉大學

\begin{abstract}
This study examined the use of imagery and the perception of success among the male and female athletes in one of the sport schools in Malaysia. A sample of 80 youth athletes (40 male, 40 female) from six various sports participated in this research. Their mean aged was 14.79, SD $=1.31$ from total of 6 sports. Participants completed the Perception of Success Questionnaire (POSQ; 1998) and Sport Imagery Questionnaires (SIQ; 1986). POSQ is used to measure the goal achievement among the gender differences while the SIQ is to seek the use of imagery skills in order to enhance their performance. Ttest analysis is used to determine the mean between the task and ego orientation and imagery among the athletes. Results showed that there was no significant difference in goal achievement between male and female athletes. It may be related to the athletes from same sport and continue their training under the same coach, therefore they have the same goal to achieve. Furthermore, One-Way ANOVA was used to examine the level of the athlete and the usage of imagery skills and goal achievement. There is no significant difference among three categories of participants with their goal achievement and focusing imagery skills except motivation specific that show a significant different among the level of participated. Recommendation for future research was all suggested.
\end{abstract}

\section{摘 要}

本研究旨在探討採用表象訓枯對成功感覺的關係, 共邀請了80位中學生運動員進行測試, 結果顯示沒有明顯的互動關係。 


\section{Introduction}

Imagining the future success can sometimes enhance people's motivation to work hard to achieve it (Vasquez \& Buehler, 2006). According to Maehr and Nicholls (1980), success and failure "are not the concrete events. They are psychological states consequent on perception of reaching or not reaching goal". It become very subjectively in determining the meaning of success for every athlete. The meaning of success to a person may not be the same to another seems they had different goals (Duda, Fox, Biddles, \& Armstrong, 1992). For examples, some athletes may define success as winning the match but some will felt they success when they perform a skill they cannot do before. Moreover, Roberts (2001) had stated that the different perception of success for different people will affect the athlete's behavior especially in the achievement situation. In relation to this, the meaning of success to an individual will influence the choice to invest in a specific activity, the amount of effort an individual will expend, and also the level of persistence shown when met by a challenge to perform that activity (Duda 1987; Duda \& Hall, 2001). Due to this, as suggested by Roberts (2001), it becomes important to understand the meaning of success for different athletes in different sports and subsequently apply the physical and psychological strategies to meet the achievement related desires.

Throughout the years, many researches had been carried out to reveal the factors for the success determination for the athletes in different sport and different levels (i.e., school, district and state). Consequently, this study examines the perceptions of success of the youth male and female athletes. Nicholls (1992) clarify that different person had different tendency to define believe about success in achievement goals. However, this conceptual and statistical differentiation of goal orientation dimensions is still limit and not clear as yet but this measurement is still important to examined whether individual difference in goal orientation (Fogarty, Tenenbaum \& Morrow, 2006).

Goal orientation is a motive state of an athlete in an achievement situation. Theory of goal achievement stated that two goal orientations manifest an individual to success. These two goals have been defined as task orientation and ego orientation (Reinboth \& Duda, 2006). Task orientation is also called perception of performance or mastery. An athlete who think they are success while they be able to master something that they cannot do before, it called task orientation. In the other hand, they are more assuming of success by mastery a challenge and self improvement. On the other hand, ego orientation is also well known as outcome or win. An athletes who assumed winning a game and finally defeat an opponent as their success are those who focus in ego orientation. As goal orientations are considered to be orthogonal (Nicholls, 1984), athletes may be high in both orientations, low in either orientation, or one of any possible combinations of low, moderate, and high (Cumming, Hall, Harwood, \& Gammage, 2002; Hodge \& Petlichkoff, 2000; Ntoumanis, Duda, \& Jagacinski, 2001; Wang \& Biddle, 2001). However, previous researches also had shown the inconsistent results among the relationship of gender difference and goals orientation which become one of the task in this study.

There had been illustrated by Michael Johnson, Olympic 400-m track champion and world record holder at $200 \mathrm{~m}$ and $400 \mathrm{~m}$ of the critical interplay between one athlete's motivation to succeed and the psychological strategies applied to meet his goal. According to his statement, mental imagery is one of the important criteria to meet the goal as he had visualize the 1996 Olympics down to the milliseconds (c.f., Harwood, Chris, Cumming, Jennifer, Hall \& Craig, 2003). As an athlete, besides physically preparation, the mental aspect is also an important technique through the hard training and, athletes must find a mental regimen that works for them. Some of the researcher argue that mental practice should involved all kind of mental preparation such as mental rehearsal, mental imagery, visualization, visualmotor rehearsal, cognitive-behavior therapy, biofeedback, progressive muscle relaxation and meditation, but Hall (2001) argue that imagery should be considered as the major component of mental practice. This can be seen through how Roger Federer, one of the professional tennis player confess that the implantation of mental imagery in his training regimen was the key to success in the field (Evanstiegel, 2008).

Mental Imagery strategies would help athletes to achieve their goal in the peak performance (Porter, 2003), given that it can help in relaxation, gaining overall confidence, overcoming anxiety as well as influences the learning and performance of skills and strategies (Hall, 2001; Martin, Moritz \& Hall, 1999). Each of these 
particular benefits represents one of five key functions imagery can serve in sport which can clarify into two major functions, cognitive and motivational functions at specific and general levels (Hall, Mack, Paivio \& Hausenblas, 1998).

Cognitive general function of imagery included applying imagery to learn the course, as part of a routine, as a tool for stimulating creativity, and to model another performance. Athletes usually used this function to learn strategies and to rehearse on how they will be performing in training and competition (Munroe, Giacobbi, Hall \& Weinberg, 2000). The cognitive specific encompassed two primary themes, which included skills acquisition and skills maintenance. This involves the rehearsal of specific skills executions (Munroe et al, 2000) as athletes commonly use this function in learning a new skill by working on technique and making corrections. Motivational general imagery can be divided into two specific components, the motivation general arousal and motivational general mastery. Motivation general arousal function of imagery is related with arousal and stress to help athletes in controlling their emotion to get "psyched up" (Munroe et al, 2000). While motivational general mastery function of imagery is associated with self-confident, mentally tough which help athletes to remain focus and positive. Furthermore, motivational specific imagery is the imagery function where athletes use to image the outcome goals and the related task to achieving those goals. The different aspects of mental imagery functions have highlighted the benefits and importance to athletes to apply the mental imagery strategies especially when dealing with goal achievement. However, several studies have shown that many athletes do not utilize imagery practices in the same regular term they approach physical practice (Barr \& Hall, 1992; Hall, Rodgers \& Barr, 1990).

Hall et. al. (2002) had indicated mental strategies that different goal orientation is a personal characteristic that might influence the usefulness of imagery. Similarly, Short, Afremow and Overby (2001) had explored how individual differences in goal orientation might influence the involvement in psychological behaviors relevant to skill execution and performance. In addition, Cumming et.al. (2002) had predicted swimmer with higher level of both task and ego orientation would engage in more frequent use of imagery focusing on demonstration on superior skills and development of personal mastery which involve in both motivation and cognitive aspect of imagery than athletes with lower levels of each goal orientation. For those athletes high in one goal orientation and low in the other, it will more focus on specific type of imagery functions related to achieve their goal orientation. Cumming also predicted that athletes high in task orientation were more tend to use cognitive function of imagery as well as motivational general mastery imagery. However, athletes high in ego orientation were predicted to engage in motivational specific imagery and motivational general arousal imagery. The study by Cumming et. al. (2002) explored the links between goal orientations and imagery use in a sample of young athletes from a single sport. However, there is lack of understanding of whether athletes from different sports with different goal orientation differently regulate their investment in mental strategies.

\section{Purpose of the Study}

This study would like to study the perception of success among the youth athletes in different sports in determining the youth sport participants is either more task oriented or ego-oriented. In linking to this study, there is also an interest in finding out the connection between the gender difference and the goal orientations. Besides goal orientation determination, as imagery is an important psychology aspect for the goal achievement, the study also involves the determination of imagery used which divided into cognitive and motivational aspects among the same respondents. Consequently, with the goal orientation and imagery usage, there is an interest to find out whether different athletes with different goal orientation involve in different types of imagery usage. These findings would probably help to understand psychological aspects of an athlete in preparation of mental training.

\section{Methodology}

\section{Samples}

This study was designed based on the descriptive methodology research. Participants were the athlete who studied and training four days per week in Pahang Sports School. A total of 80 athletes (40 Male and 40 Female) from 13-17years ( $\mathrm{M}=14.79$ years, $\mathrm{SD}=1.31)$ were participated in this study. These samples were made up of athletes from variety of sports (football, netball, hockey, 
athletic, takraw and archery). Participant in the study was voluntary, they have sign an informal letter and release letter from parents.

\section{Instrumentation}

The questionnaires were divided into two parts, namely: a simple demographic part and questionnaires for imagery and perception of success.

\section{Demographic Variables}

All samples supplied relevant demographic data including age, gender, race, religion, type of sport involved, and their competitive level.

\section{Sport Imagery Questionnaire (SIQ)}

The Sport Imagery Questionnaire (SIQ; Hall, Mack, Paivio, and Hausenblas, 1998) was used to examine the general use of imagery approach used by the respondents in their sports. The SIQ consisted 30 items on a 7 -point Likert scale (1= rarely, 7 =often) which comprise five subscales (Figure 1): Cognitive Specific (CS), Cognitive General (CG), Motivation Specific (MS), Motivation General-Arousal (MG-A) and Motivation General-Mastery (MG-M). Although research noted that the alpha reliability coefficient of above .70 (SIQ) by using the adult samples (Hall et.al.,1998 ) but it also validated for children as young as 10 (Cunning \& Ste-Marie., 2001).

Figure 1. Terms and Definition of the Sport Imagery Questionnaires (SIQ-Hall et al, 1998).

\begin{tabular}{|c|c|c|}
\hline Sub-scale & Descriptions & Sample of Questions \\
\hline Cognitive Specific (CS) & $\begin{array}{l}\text { In this type of imagery, the athlete imagines himself } \\
\text { correctly executing a specific sport skill during } \\
\text { competition. }\end{array}$ & $\begin{array}{l}\text { I can consistently control the } \\
\text { image of a physical skill. }\end{array}$ \\
\hline Cognitive General (CG) & $\begin{array}{l}\text { In this type of imagery, the athlete imagines himself } \\
\text { reviewing team defensive strategies in sport } \\
\text { involved. }\end{array}$ & $\begin{array}{l}\text { I make up new plans/ } \\
\text { strategies in my head. }\end{array}$ \\
\hline Motivation Specific (MS) & $\begin{array}{l}\text { In this type of imagery, the athlete imagines himself } \\
\text { in a specific setting that is highly motivating. }\end{array}$ & $\begin{array}{l}\text { I imagine other athletes } \\
\text { congratulating me on a good } \\
\text { performance. }\end{array}$ \\
\hline $\begin{array}{l}\text { Motivation General_ } \\
\text { Arousal(MG_A) }\end{array}$ & $\begin{array}{l}\text { In this type of imagery, the athletes imagine himself } \\
\text { in a general sport situation exhibiting the ability to } \\
\text { control anxiety }\end{array}$ & $\begin{array}{l}\text { I can re-create } \mathrm{n} \text { my head } \\
\text { the emotions I feel before I } \\
\text { compete. }\end{array}$ \\
\hline $\begin{array}{l}\text { Motivation } \\
\text { General Mastery (MG_M) }\end{array}$ & $\begin{array}{l}\text { In this type of imagery, the athletes imagines himself } \\
\text { in a general sport situation exhibiting the ability to } \\
\text { remain focused }\end{array}$ & $\begin{array}{l}\text { I image giving } 100 \% \text { during } \\
\text { an event/game. }\end{array}$ \\
\hline
\end{tabular}

Sources: Adapted from Paivio's two dimensional model, Hall, Mack, Paivio and Hausenblas (1998) 


\section{Perception of Success Questionnaire (POSQ)}

The Perception of Success Questionnaire (POSQ) consisted 12 items on a 5-point Likert scale (1= Strongly Agree, 5= Strongly Disagree). The POSQ is a twelve item test of task/mastery and ego/competitive orientation with six item in each subscale (Robert, Treasure \& Balague, 1998). An example of the question is "I reach a target I set to myself". All scales have been shown to have alpha coefficient raging .82 for task orientation and .91 for ego orientation. These items were used in this study to find out the respective orientation of the respondents.

\section{Procedures}

Prior to start to deliver the questionnaire, the researcher had sought the permission from the school principal and their coaches. Participants were approached before evening training sessions for their sports. The researcher explained the purpose of the study and information of the completion of the questionnaire. Those who volunteer were asked to complete two questionnaires in full as presented without referring to another person. The respondent had been request to answer the POSQ and follow by SIQ. The completed questionnaires were collected back directly before they start their training.

\section{Analysis of Data}

All data were analyzed using the Statistical Package of Social Science (SPSS) program software version 16.0. An independent T-test was used to compare the mean between male and female on task/ ego oriented and subscale of imagery. The ANOVA also used to identify the perception of athlete in different level about goals achievement and using imagery in their sports.

\section{Results}

\section{Descriptive analysis for SIQ and POSQ Data}

By using the Cronbach's alpha, the internal consistency of items measuring each of SIQ and two subscales for POSQ, were calculated for both samples. The results show that most of the scales have a acceptable internal consistency, with alpha coefficients ranging from .51 to .88. The POSQ and SIQ questionnaire which contain task and ego oriented, six sub-scale of imagery also show a high internal reliability of .774 and .888 .

Table 1. Descriptive Statistics and Reliability Coefficient for Goal Orientation and Imagery for the Sample (n=80).

\begin{tabular}{lccc}
\hline Variables & Means & SD* & Cronbach's alpha \\
\hline SIQ & 4.97 & .84 & .888 \\
POSQ & 2.24 & .58 & .774 \\
Imagery subscale (Likert Scale 1-7) & & & \\
Cognitive General (CG) & 4.84 & .92 & .654 \\
Cognitive Specific (CS) & 4.96 & 1.03 & .779 \\
Motivation Specific (MS) & 5.30 & 1.07 & .711 \\
Motivation General_Arousal (MG_A) & 4.71 & .95 & .608 \\
Motivation General_Mastery (MG_M) & 5.03 & 1.02 & .714 \\
POSQ subscale (Likert scale 1-5) & & & .513 \\
Task oriented & 2.32 & .58 & .823 \\
Ego oriented & 2.17 & .70 & \\
\hline
\end{tabular}


Table 2. Independent T-test Results on SIO sub-scale according to Gender.

\begin{tabular}{|c|c|c|c|c|c|}
\hline Sub-scale & Gender & $\mathbf{n}$ & Mean & SD & Sig \\
\hline \multirow[t]{2}{*}{ Cognitive Specific (CS) } & Male & 40 & 5.0083 & .9555 & .655 \\
\hline & Female & 40 & 4.9042 & 1.1164 & \\
\hline \multirow[t]{2}{*}{ Cognitive General (CG) } & Male & 40 & 4.7625 & .9182 & .435 \\
\hline & Female & 40 & 4.9250 & .9344 & \\
\hline \multirow[t]{2}{*}{ Motivation specific (MS) } & Male & 40 & 5.4750 & .9875 & .129 \\
\hline & Female & 40 & 5.1122 & 1.1224 & \\
\hline \multicolumn{6}{|c|}{ Motivation General_Arousal } \\
\hline \multirow[t]{2}{*}{ (MG_A) } & Male & 40 & 4.5917 & .8465 & .258 \\
\hline & Female & 40 & 4.8333 & 1.8446 & \\
\hline \multicolumn{6}{|c|}{ Motivation General_Mastery } \\
\hline \multirow[t]{2}{*}{ (MG_M) } & Male & 40 & 4.4954 & .9755 & .503 \\
\hline & Female & 40 & 5.1083 & 1.0706 & \\
\hline
\end{tabular}

From the analysis of T-test, result had shown that there were no significant differences in both SIQ and
POSQ test between the female and male which value alpha $\mathrm{p}>05$.

Table 3. Independent T-test Result on POSQ sub-scale according to Gender.

\begin{tabular}{llllll}
\hline Sub- scale & Gender & $\mathbf{n}$ & Mean & SD & Sig \\
\hline \multirow{2}{*}{ Task } & Male & 40 & 2.3208 & .5876 & .795 \\
& Female & 40 & 2.3167 & .5796 & \\
& & & & .1185 & .062 \\
Ego & Male & 40 & 1.9667 & .0947 & \\
& Female & 40 & 2.3625 & \\
\hline
\end{tabular}

The above results show both male and female athletes show they are task oriented and ego oriented in POSQ test, indicate that the athletes tested have ability to be either task or ego involved in their games. Compare in term of gender, although male shown a little bit higher tendency toward ego orientation, but generally the results show there is no significant difference between the achievement goals by different gender ( $p$ >.05). 
Table 4. One-way ANOVA Analysis sub-scale with Level of Participants.

\begin{tabular}{|c|c|c|c|c|}
\hline Subscale & $\begin{array}{l}\text { Level of } \\
\text { participants }\end{array}$ & $\mathrm{n}$ & Mean & sig \\
\hline \multicolumn{5}{|l|}{ Imagery } \\
\hline Cognitive Specific (CS) & $\begin{array}{c}\text { School } \\
\text { District } \\
\text { State }\end{array}$ & $\begin{array}{c}23 \\
5 \\
52\end{array}$ & $\begin{array}{l}5.1333 \\
4.8913 \\
4.9679\end{array}$ & .888 \\
\hline Cognitive General (CG)) & $\begin{array}{c}\text { School } \\
\text { District } \\
\text { State }\end{array}$ & $\begin{array}{c}23 \\
5 \\
52\end{array}$ & $\begin{array}{l}4.7000 \\
4.4565 \\
5.0288\end{array}$ & .420 \\
\hline Motivation Specific (MS) & $\begin{array}{c}\text { School } \\
\text { District } \\
\text { State }\end{array}$ & $\begin{array}{c}23 \\
5 \\
52\end{array}$ & $\begin{array}{l}5.5607 \\
4.8116 \\
5.4808\end{array}$ & $.034^{*}$ \\
\hline Motivation General_Arousal (MG_A) & $\begin{array}{c}\text { School } \\
\text { District } \\
\text { State }\end{array}$ & $\begin{array}{c}23 \\
5 \\
52\end{array}$ & $\begin{array}{l}4.1333 \\
4.7319 \\
4.7596\end{array}$ & .720 \\
\hline Motivation General_Mastery (MG_M) & $\begin{array}{c}\text { School } \\
\text { District } \\
\text { State }\end{array}$ & $\begin{array}{c}23 \\
5 \\
52\end{array}$ & $\begin{array}{l}4.8000 \\
4.9348 \\
5.0962\end{array}$ & .373 \\
\hline $\begin{array}{ll} & \text { Goals achievement } \\
\text { Task oriented }\end{array}$ & $\begin{array}{c}\text { School } \\
\text { District } \\
\text { State }\end{array}$ & $\begin{array}{c}23 \\
5 \\
52\end{array}$ & $\begin{array}{l}2.4333 \\
2.2971 \\
2.3173\end{array}$ & .895 \\
\hline Ego oriented & $\begin{array}{c}\text { School } \\
\text { District } \\
\text { State }\end{array}$ & $\begin{array}{c}23 \\
5 \\
52\end{array}$ & $\begin{array}{l}1.9000 \\
2.0797 \\
2.2276\end{array}$ & .487 \\
\hline
\end{tabular}

$* \mathrm{P}<.05, * * \mathrm{p}<.01$

Table shows the imagery used and the goals achievement by the athletes in different level of participating in sports. There are no significant difference

\section{Discussion}

This study examined the focus on the goal achievement and the types of imagery used among male and female athletes. The result of the study showed the total of 80 youth participant those who represent their school, district and state in several of sports (hockey, football, netball, takraw, athletic and archery). Some of them are still as a beginner in the field of sport. among three categories of participants with their goal achievement and focusing imagery skills except motivation specific that show a little significant different among the level of participated $(\mathrm{F}(2,77)=3.528, \mathrm{p}<.05)$.

From the result, all athletes show their higher interest in either task or ego oriented. The finding indicated that the athletes assumed training hard; mastering a skill they cannot do before and able to beat down other opponents are both the important criteria for them to feel success. One possible reason for this finding is that all respondent shown they are both ego and task oriented since there are still young teenagers (13-17 years) who had just start their sport careers. 
Youth athletes in this age range would probably defined success as winning and beating others but at the time they still need to work hard and go through training in mastering their sports under their coach. They try to put more effort in learning a new skill in order to achieve their goals. Further studies in determining the age range and goal orientation would probably have a better understanding with the result obtained. On comparing the gender differences with the goal orientation, through the study, both male and female athletes either from different types of sports and different levels showed no significant differences with the goals achievement. There are no different among gender with their goals achievement. This result is in accordance with past study (Omar-Fauzee, Lee, Soh \& Abdul Latif, 2008) which have also shown that there are no gender different on achievement goals. Perhaps, in both studies employing samples shows that the level of goal among Malaysia male athletes will still behind than others. Thus, the implication is that their motivation to achieve goals are still lacking. This is true when compare it with other studies by Ntoumanis (2001); Thorkildsen and Nicholls (1998), that male show higher focusing in ego orientated which means they seek for winning the game and tend to use normative criteria when comparing their abilities with others (Theodosiou \& Papioannou, 2006; Sit \& Lidner,2004) and they are very motivated to show a skill due to their pressure of doing well (Vansteenkiste \& Deci, 2003) while female are more desire to work hard to reach their goals (Bouffard, Boisvert, Vezeau \& Larouche, 1995). Once again, the different with the result from the previous researcher would probable govern by different range of ages from the respondents, or perhaps the mastery level of Malaysia athletes were still lacking. Perhaps the culture may play role in the findings. It is interesting to know what should be the results if comparison has been done with the other South East Asia country such as Thailand, Indonesia and Philippines. Are the culture and the gender giving the different finding from Western World?

Porter (2003) stated that using the imagery help one to be more confident and able to achieve higher performance. This is because mental imagery is an interesting device for influencing thought, affective states, and athletes' behavior in sport and exercise (Morris, Spittle \& Watt, 2005). Instead, Paivio (1985) presented a model which stated at cognitive and motivation functions that influence sport performance. Furthermore, study by Raweewat et. al. (2009) on Malaysia athletes shows that both male and female athlete practices using imagery in their athletic life but not regularly. However, his study showed there are no significant different of the imagery usage between male and female. It is somewhat surprising that no different between male and female in imagery usage somehow they are in the same range of age. Perhaps, Malaysia female athletes have imagery power than male counterparts. Due to the non-significant results from the gender (male and female), it is suggested that more longitudinal studies as well as qualitative studies should be coordinated to examine why such situation occurs.

Results also shows there is no significant different between imagery and the level of the athlete except motivation specific (MS). The MS type of imagery is the type where athletes imagery himself in a specific setting in a highly motivation mood. If we go back to the earlier discussion, it seems that the Malaysia athletes' mastery skills were lacking is true. This can be seen in the relationship between the MS and level of participants. The highest MS only for those who represent school if compare to other level (district and state). They can imagine themselves at the highest motivation level at the specific setting. This means that their ability cannot be beaten by others at that level. However, their MS were low at the state level, it became even worst at the district level. Perhaps, this is due to the environment and the challenge they got from the competition. The less capable they were, the less MS type of imagery they will felt. This situation should be change if Malaysia athletes want to excel at International level whereby the highest level of the athletes should be using more MS rather than lower level athletes.

The study cannot run from limitation that can be overcome in the next study. One of the limitation is that not all of the athletes have the same ability to endure the imagery. Some of them might have difficulties to do the visualization kinesthetic imagery, therefore results might be varied. If Malaysia wants to be among the sport champion in the world, further study should be conducted to search for the visualization weaknesses among Malaysia youth athletes.

In conclusion, result from the present study show that there is no significant different between gender and the goal achievement among Malaysia athletes. On the other hand, it also shows the level of the athletes have also given a big implication for Malaysia athletes. 
Therefore, further study may to understand why such level of experiences cannot conduct imagery appropriately. It is more beneficial if the study also be conducted longitudinally and qualitative in the future. Perhaps, study should also compare with other South East Asia country in order to understand the similarity of culture in this region among athletes.

\section{References}

Barr, K., \& Hall, C. (1992). The use of imagery by rowers. International Journal of Sport Psychology, 23, 243-261.

Bochiaro, M. (2004). The use of imagery by collegiate athletes during their of-season. Master's thesis, Miami University.

Bouffard, T. Boisvert, J. Vezeau, C., \& Larouche, C. (1995). The impact of goal orientationon self regulation and performance among college students. British Journal of Eeducation Psychology, 65, 317-329.

Callow. N., \& Hardy. L (2001). Types of imagery associated with sport confidence in netball players of varying skill levels. Journal of Applied Sport Psychology. 13, 1-17.

Cumming, J. C., Hall, C., Harwood, \& Gammage, K. (2002). Motivation orientation and imagery use: A goal perspective. Journal of Sport Science, 20, 127-136.

Cumming, J., Hall, C., Harwood, C. G., \& Gammage, K. (2002). Motivational orientations and imagery use: A goal profiling analysis. Journal of Sport Sciences, 20, 127-136.

Duda, J. L., Fox, K, R., Biddle, S. J. H \& Armstrong, N. J. (1992). Children's achievement goals and belief about success in sport. British Journal of Educational Psychology. 62(3), 313-323.

Duda, J. L., \& Hall, H. (2001). Achievement goal theory in sport: Recent extensions and future directions. In R. N. Singer, H. A. Hausesenblas, \& C. m. Janelle eds.), Handbook of sport psychology (pp. 417-443). New York, NY: Wiley \& sons.
Fogarty, G.J., Tenenbaum, G., \& Morrow, K. (2006). Psychometric evaluation of goal orientation measure in sport. In M. Katsikitis (Ed.), Proceedings of the 2006 Joint Conference of the APS and NZPsS, pp120-124. Auckland, NZ, 26-30 September 2006.

Hall C., Mack D., Paivio, A., \& Hausenblas, H. (1998). Imagery use by athletes: development of the sport imagery questionnaire. International Journal of Sport Psychology, 29, 73-89.

Hall, C. (2001). Imagery in sport and exercise. In R. Singer, H. Hausenblas, \& C. Janelle (Eds.), Handbook of Sport Psychology (pp. 529 - 549). New York, NY: John Wiley \& Sons, Inc.

Hall, C., Rodgers, W., \& Barr, K. (1990). The use of imagery by athletes in selected sports. The Sport Psychologist, 4, 1-10.

Harwood, Chris; Cunning, Jennifer; Hall \& Craig. (2003). Imagery use in elite youth sport participants: reinforcing the applied significance of achievement goal theory. Research Quarterly for Exercise and Sport. 74(3), 292-300.

Hodge, K., \& Petlichkoff, L.M. (2000). Goal "profiles" in sport: A cluster analysis. Journal of Sport and Exercise Psychology, 22(3), 256-272.

Jagacinski, C. M., \& Duda, J. L. (2001). A comparative analysis of contemporary achievement goal orientation measures. Educational and Psychological Measurement, 61, 1013-1039.

Li, F. Z., Harmer, Peter; Acock \& Alan (1996). The task and ego orientation in sport questionnaires: construct equivalence and mean differences across gender. Research Quarterly for Exercise and Sport. 18(4), 392-407.

Maehr, M. L., \& Nicholls, J. G. (1980). Culture and achievement motivation: a secong look. In $\mathrm{N}$. Warren(ed.), Studies in cross-cultural psychology (Vol. 2, pp. 221-67). London: Academic Press.

Martin, K. A., Moritz, S. E., \& Hall, C. (1999). Imagery use in sport: A literature review and applied model. The Sport Psychologist, 13, 245-268. 
Moran, A. P. (2004). Sport and exercise psychology. New York: Routledge.

Smith, S. B. (2007). The influence of performance level and setting on collegiate athletes motivation profiles. Master's thesis, Brigham Young University.

Morris, T., Spittle. M., \& Watt, A.P. (2005). Imagery in sport. USA: Human Kinetic. Lavalle. D., William. J. M \& Jones. M. V. (2008). Key studies in sport and exercise Psychology. New York: McGraw-Hill.

Munroe, K. J., Giacobbi, P. R., Hall, C. R., \& Weiberg, R. (2000) The four Ww of imagery use: where, when, why, and what. The Sport Psychologist, 14, 119-137.

Ntoumanis, N. (2001). Empirical Links between achievement goal theory and self-determination theory in sport. Journal of sport science, 19, 397-409.

Omar_Fauzee, M. S., Lee, H. S., Soh, K.G. \& Abdul Latif, R (2008). The Relationship between the task and ego orientation and coping strategies among universities athletes. The ICHPER.SD Journal of Research, 3, 107-111.

Raweewat, R., Omar_Fauzee, M. S., Soh, K. G., Abdullah, M. C., Chairat, C., Nazaruddin, M. N., \& Nordin, H. (2009). Evaluating the relationship of imagery and self-confidence in female and male athletes. European Journal of Social Sciences. 10(1).

Reinboth, M., \& Duda, J. L. (2006). Perceived motivation climate, need satisfaction and indices of well-beign in team sports: a longitudinal perspective. Psychology of Sport and Exercise, 7, 269-286.

Roberts , G. C., Treasure, D. C., \& Balague, G (1998). Achievement goals in sport: the development and validation of the perception of success questionnaire. Journal of Sport Science, 16, 337-343.

Short, S. E., Afremow, J., \& Overby, L. (2001). Using mental imagery to enhance children's motor performance. Journal of Physical Education, Recreation and Dance, 72, 19-23.
Theodosiou, A., \& Papaiaoannou, A. (2006). Motivation climax, achievement goals and metacognitive activity in physical education and exercise involvement in out-of-school settings. Psychology of Sport and Exercise, 7, 361-379.

Thorkildsen, T.A., Z \& Nicholls, J. G. (1998). Fifth graders' achievement orientation and belief: individual and classroom differences. Journal of Education Psychology, 90, 179-201.

Wang, \& Biddle, J. H. (2001). Motivation and selfperception profiles and links with physical activity in adolescent girls. Journal of Adolescence, 6, 667-701.

Vasquez, N. A., \& Buehler, R. (2007). Seeing in success: Does imagery perpesctive influence achievement motivation? Personality and Social Psychology Bulletin, 33, 1392.

Evanstiegel. (2008, February 26). Mental imagery: Does it really benefit athletic performance. Message posted to SERENDIP electronic mailing list, archieved at http://www. W3c.org/TR/1999/ \&EC-html401-19991224/ loose.dtd.

\section{Correspondence:}

Dr. Kim Geok SOH

Associate Professor

Sports Studies Department, University Putra Malaysia, MALAYSIA

Email: kimgeoks@yahoo.com 